\title{
The Use of Mobile Apps by Radiology Journals
}

\author{
George Rahmani ${ }^{1}$ (D) Peter A McCarthy ${ }^{1,2}$
}

Published online: 21 June 2017

(C) Society for Imaging Informatics in Medicine 2017

Dear Editor,

Mobile applications (apps) have grown exponentially in number since they were first introduced in 2008. There are now over 2.2 million apps on Apple's iOS platform. Academic journals often use apps to provide another platform for their readers and subscribers to easily access their content. We aimed to determine whether radiology journals have adopted apps and whether those journals with apps have a higher impact factor than those without.

The journals listed in the Institute of Science Information Web of Science subject category "radiology, nuclear medicine, and medical imaging" were searched in the Apple ${ }^{\circledR}$ App Store ${ }^{\mathrm{TM}}$. The journal name, category, impact factor, and publisher were recorded.

A total of 112 radiology, nuclear medicine, and medical imaging journals were identified, with 4 being excluded as they are no longer actively publishing. Of the remaining 108 journals, 20 (18.5\%) of journals had a dedicated app for their subscribers to view the content of their journal directly (Table 1). These journals had a higher mean impact factor when compared with those journals that did not have a dedicated app ( 2.859 vs. 2.103 ; $p=0.031)$. The publishing company with the most journals providing dedicated apps for their readers was $\operatorname{Springer}(n=8)$.

Of the 108 identified radiology journals, 20 have a dedicated mobile app to allow readers another avenue to access the journal content. These journals appear to have a higher impact factor. It may be that journals with higher impact factors have more resources at their disposal and have invested in developing

George Rahmani

george.rahmani@gmail.com

1 Galway University Hospitals, Newcastle Road, Galway, Ireland

2 National University of Ireland, Galway, Ireland and maintaining their own app. It is also possible that these journals have a wider readership because of their apps, which in turn could eventually lead to more citations and higher impact factors.

Almost one fifth of radiology journals provide a dedicated mobile app to allow ready access to the journal's content for their readers and subscribers. These journals have an overall higher impact factor compared with radiology journals without a dedicated mobile app. We feel that radiology journals and their publishers should be encouraged to design and maintain mobile apps for their readers.

Table 1 Journals with mobile applications and their impact factors

\begin{tabular}{lll}
\hline Journal & Publisher & $\begin{array}{l}\text { Impact } \\
\text { factor }\end{array}$ \\
\hline Cancer imaging & Springer & 1.47 \\
Cancer Radiotherapie & Elsevier & 1.299 \\
Cardiovascular and Interventional radiology & Springer & 2.144 \\
Clinical Radiology & Elsevier & 2.151 \\
European Journal of Nuclear Medicine and & Springer & 5.537 \\
$\quad$ Molecular Imaging & Springer & 3.64 \\
European Radiology & Elsevier & 0.101 \\
Feuillet de Radiologie & Elsevier & 7.815 \\
JACC-Cardiovascular Imaging & Springer & 0.874 \\
Japanese Journal of Radiology & Springer & 1.406 \\
Journal of Digital Imaging & Wiley & 3.25 \\
Journal of Magnetic Resonance Imaging & Wiley & 1.182 \\
Journal of Medical Imaging and Radiation & & \\
$\quad$ Oncology & Wiley & 1.625 \\
Journal of Neuroimaging & Springer & 2.929 \\
Journal of Nuclear Cardiology & Elsevier & 2.929 \\
Journal of The American College of Radiology & Wiley & 3.782 \\
Magnetic Resonance in Medicine & Springer & 1.525 \\
Pediatric Radiology & RSNA & 2.523 \\
RadioGraphics & RSNA & 6.798 \\
Radiology & Wiley & 4.197 \\
Ultrasound in Obstetrics \& Gynecology & & \\
\hline
\end{tabular}

